\section{Ethics, Reproduction and Genetic Control}

Edited by Ruth Chadwick, 200 pages, London, £8.99, Routledge, 1987

The first child born as a result of in vitro fertilisation (IVF) is now over ten years old. After a decade of technical marvels in reproduction including embryo transfer and freezing, and preimplantation genetic diagnosis, follows the uncertain business of creating moral terms of reference to deal with their application. Ruth Chadwick's collection of essays attempts to do just this and she has gathered some of the world leaders in their prospective fields of science, medicine and law to address ethical issues. It is revealing that the Director of Research of France's CNRS, Jerome Lejeune, emphasises fetal-centred debate and minimises women's role in reproduction to that of carriers by comparing embryos to selfdetermining astronauts and the role of a mother to that of 'a life capsule' and 'the mother ship'.

Chadwick establishes reproduction as more than a private act that should be accountable to public policy. The failure of policy formation in Britain is put forward by the ethicist, $\mathrm{R} M$ Hare who criticises the Warnock Report for its lack of an ethical standpoint which has left the reproductive technology debate open to intuition and prejudice (as with the issue of whether to continue with embryo research or not). He offers a utilitarian approach which would enable state control and public accountability for the way in which reproductive techniques and related applications such as surrogacy are regulated. In a religious context the Board for Social Responsibility of the Church of England argues for the same thing. The board's article embeds issues of reproductivity within the Christian ideal of a proper procreative place (marriage) and from the Protestant perspective, views most of the technologies (including embryo research) as ways of sustaining 'the goods' of Christian marriage. Both sides agree that the technologies should be limited to the nuclear family for the sake of the child although it has not been proven that this is the best place for raising children.

The dichotomy between religious morals and the value of technological development is revealed in most of the arguments in this collection in that restrictions on the use of these techniques are qualified chiefly by a hesitation in embryo manipulation. In both sides of the argument mothers rate hardly any mention and the idea that an ethic could be developed from their particular experience is raised only briefly by Chadwick in a reference to Mary O'Brien's theory of 'reproductive consciousness' and is not related to the discussion as a whole. The result of this dichotomy, which I see as false, is a fetal-centred debate and an ethic which effectively denies women's procreativity both physically and as a thoughtful undertaking.

In the second half of the text Chadwick examines genetic engineering, both pre-implantation and post-conception. She concludes as does W French Anderson, one of America's leading geneticists, that the engineering of human cells, both somatic and germline (which affects subsequent generations' genetic make-up) are morally justified if used to prevent or cure disease but not to enhance human qualities. However, another wellestablished genetic scientist, Robert Sinsheimer, reveals there is more to genetic engineering than the control of disease: 'We can be the agent of transition to a whole new pitch of evolution. This is a cosmic event'. The discussion of new eugenics practised in Singapore by C K Chan is a sobering example of the possible realisation of such dreams. In Singapore the state actively promotes reproduction among the educated and prevents it in the poor and un-educated in the hope of creating a super-intelligent gene pool.

Sex-selection is another form of eugenics which reproductive technology facilitates. Dharma Kumar properly defines the practice of routine amniocentesis followed by abortion of female fetuses in India as a social rather than technological problem. My concern with his conclusions, as with most of the ethics discussed in this collection, is that the crucial roles feminism as activism and theory have played (it was feminists who drew public attention to female infanticide in India) is ignored or misrepresented. Meanwhile, various morals are assigned to the embryo and an ethic which promotes technological solutions to social problems is sustained.

A J BURFOOT Assistant Professor Department of Sociology Queens University, Kingston, Canada

Human IVF, Embryo Research, Fetal Tissue for Research and Treatment, and Abortion: International
Information

Jennifer Gunning, 44 pages, London, £7.50, HMSO, 1990

This summary of the current position as regards the law and practice of in vitro fertilisation (IVF), fetal research and abortion in countries providing IVF allows comparison of the situation 